\title{
Navigate Paradox in Organizations: The Implications of Combining Theory of Paradox with Practice
}

\author{
Mourad Mechiche \\ Independent Scholar, Vihastenkarinkatu 21-23 G, Raahe, Finland
}

\begin{abstract}
The search to uncover the implications of combining paradox with real life practice have led scholars into an impasse and yielded paradoxical results that are still theoretical in nature. This qualitative research draws on a variety of studies to frame an approach to paradox using insights from Zen psychology, brain plasticity and behaviour. Considering a change in behaviour entails plasticity in the brain, and willingly engaging in attempts to navigate paradox is per se a change in behaviour, thus, it is apparent that once we push a brain by means of behaviour change to become plastic to the chaotic, irrational and ambiguous nature of paradox, it adjusts itself to satisfy this newly adopted behaviour considering that literature contributed little to merge paradox theory with practice. The change in behaviour is facilitated by a stimulus model which will be the ultimate product of my research on paradox.
\end{abstract}

Keywords: Paradox, Learning model, practice, Behaviour and organizations

DOI: $10.7176 / \mathrm{EJBM} / 12-29-06$

Publication date:October $31^{\text {st }} 2020$

\section{Introduction}

Paradoxes are novel, fun and ignite the need to solve the moment they are heard by individuals. However, paradoxes are serious, they raise troublesome issues, breed confusion and ambiguity and often digress from reason and rationality (Brulhart, Grimand, Krohmer, Oiry, \& Ragaigne, 2018; Fletcher \& Olwyler, 1997; Handy, 1995; Johnson, 1992; Kouzes \& Posner, 1995; Sainsbury, 1995; Smith \& Lewis, 2011; Sorensen, 2003; Sundaramurthy \& Lewis, 2003). Books, articles and papers on paradox and its appearance, impacts and implications especially in the business domain are numerous, and new manuscripts on the different theoretical applications of paradox are published at a high rate. Nonetheless, the practicality possibilities of this plethora of frameworks, understandings, approaches and or strategies remain in scarcity for both businesses and academia.

This paper's purpose is to explore the main streams of possible practice approaches that would complement the existing literature, seek supporting conclusions from other research fields such as Brain plasticity, Behaviour and outline the implications of combining paradox with practice in the business sphere. My research is essentially exploratory in nature. The claim of this paper is; the more an individual willingly exposes oneself to the ambiguity, uncertainty and irrationality of paradox, and thinks beyond, automatically the individual is paving a behaviour that in turn, ignites plasticity in the brain in order to satisfy it, hence the rules of practice are applied, and as a result, the more one engages paradox, the more one gets better at managing, coping and/or navigating its tensions that can extend even further to reach solution where the tensions applied will seem irrelevant.

\section{Conceptual foundation}

Paradox is inherent aspect of nature and its roots go deep in the ancient teachings throughout the world and marked in a wealth of literatures (Lewis, 2000; Neuwirth, 2018; Smith \& Lewis, 2011). A common understanding of paradox is interesting, novel and provoking tensions of a sort (Poole \& van de Ven, 1989). Smith and Lewis, 2011 defined paradox as "...contradictory yet interrelated elements that exist simultaneously and persist over time". To Rescuer (2001) it is a dissonance, to Roy Sorensen paradox is a form of riddle, to Gareth Matthews it is a conflict that is trapped within a conceptual truth and for John Leslie Mackie it is a set of irregularities. There are many variations to the understanding of what paradox is and the way it is perceived. To make the matter even complex, linguistics have categorized contradictions into several figures such as oxymora, enantiosis (contradiction in adiecto) and paradox, the use of them is often unclear and interchangeable (Neuwirth, 2018) that leaves room for misunderstandings and breads more questions than answers such as, what is really paradox?. Can simple tensions or contradictions between two poles be considered a paradox? (Czakon, Fernandez, \& Minà, 2013). Hart, 2006 noted that Paradox is not a mere contradiction and the advantage of its nature is that, it stimulates discussion (Hart, 2006); This claim was sustained by Cajon, 2013 that stated “...paradox inspires and breeds research" (Czakon et al., 2013).

The number of existing real-life practical tools that help in navigating, coping, or managing paradox are close to none. Some prominent frameworks such as van de Ven (1989), who suggested the four generic ways to deal with paradoxes. Johnson's concept "Polarity Mapping" for identifying and managing unsolvable problems, and Fletcher's pendulum for managing dualities and self-discovery. Nonetheless, theoretical approaches, strategies, guidelines and or theories are abound, that in fact, never point a practical $\mathrm{HOW}$, but rather a mere direction to 
follow when faced with paradox.

Henceforth, it is a given that scholars of paradox have different views of paradox in business, and according to every author, there is a set of does and don'ts to cope, manage navigate or just accept paradox. Universal theory, guideline, and/or a fixed framework to paradox, have not been established nor been agreed upon in any form. Also none that can firmly say or predict that such a way will most definitely lead to navigate paradox, this former rests on the leader's shoulders to decide so, and to the business performance to validate the efforts invested in the process, and an example of such can be seen in the superiority of Singapore airlines in the airline business.

Taking in consideration the different perspectives in which paradox is perceived, studies of brain and especially brain plasticity have discovered the strong relationship between what we are set to do and the different ways out brain can change itself to help us achieve it, in other words, the way that a newly adopted behaviour can reshape the brain on different levels to adapt to this behaviour and make the individual excel in it (Kolb, 1995). According to Skinner, 2012 human behaviour is a changing, fluid and fading process of the responses of an individual to internal and/or external stimuli. That been said, the relationship between the perspectives in which paradox is perceived and engaged, and a change in behaviour are close. As Skinner, 2012 puts it, the responses of an individual to paradox is per se a behaviour, and the perspectives sought are directions that are believed to be leading to navigating, managing, coping, and/or accepting paradox. In turn, this process pushes the brain to adjust itself to host this newly adopted behaviour and allow the individual to get better at it. Thus, as an explanatory example, engage in doing or practicing a task such as playing a musical instrument or discovering a new way to kick a ball better can change the structure of the brain on some level and to some extent.

The rich literature on brain plasticity and behaviour and the insights it provided in understanding both brain and behaviour have not been associated with paradox and its presence in business, however, knowing that the more one deliberately engages with paradox and persisting on the idea to navigate its tensions, will help in reshaping the individual's brain to become able to deliver optimal solutions, is of utmost importance. As Charles Handy emphasized, the need to look at world from a different lens is of utmost importance (Handy, 1995). And in this case, we just need to look at paradox from a different lens, and it will be clear that paradox offers solutions only on the level where its current tensions become irrelevant.

\section{Introduction To Practice}

Practice is a concept centred on activities commonly accepted that contribute in shaping patterns of how issues are handled or to be handled amongst practitioners. To Bourdieu, 1990, practice is "Improvisatory"(Bourdieu, 1990), in other words it is a process that is performed spontaneously and without preparation as an answer to a provided knowledge of some sort. To Nicolini et al., 2003 Practice refers to "as what persons say, imagine, conceive, and produce, and think while attempting to carry out activities" (Nicolini, Gherardi, \& Yanow, 2003). To Howard practice is a form of playing games (Howard, 2012a) taking in consideration that in games, experience is incited hence cannot be predicted in details (Beech, Burns, de Caestecker, MacIntosh, \& MacLean, 2004) which suggests that experience is a product of willingness to self-change (Trottier, Polivy, \& Herman, 2009) and ultimately can be considered a behavioural change. According to Clegg 2002, practice involves handling present and apparent polarities simultaneously (Clegg, Vieira de Cunha, \& Cunha, 2002) that overlap with the latent paradoxical tensions of a given issue in business organizations.

Practice is known to research by three different approaches. The first is Marxist Tradition in which focusing on cognitive aspects is deliberately avoided where there is propensity for knowledge to be dominant in the process. Second is Phenomenology that is based on interactions, in other words, knowledge is and can only be tapped into through interactions. The third approach is long been the subject of influential sociologists such as Bourdieu, Garfinkel, and Giddens (Schatzki, 2012; Schatzki, Knorr-Cetina, \& Savigny, 2001).

A prominent example that englobes both the concepts of paradox and practice is serious play. Serious play is a term used to depict the act of deliberately accomplishing important tasks through fun and playful conducts (Beech et al., 2004), where play according to Heracleous, 2005, is the pursuit of uncertain, senseless and often irrational activities and provides a risk free environment to test, experiment and innovate (Loizos Heracleous, 2005). Thus, Statler et al. 2011, believed that it can be a link to connect theory and practice. 
Serious play as a methodology has been used in different organizational contexts (See table 1).

\begin{tabular}{|l|}
\hline Organizational context \\
\hline Strategy \\
\hline Innovation \\
\hline Strategy \\
\hline Strategy \\
\hline Organizational change \\
\hline Strategy \\
\hline Strategy \\
\hline Organizational development \\
\hline Scenario development \\
\hline Leadership development \\
\hline Organizational decision-making \\
\hline Strategy \\
\hline
\end{tabular}

\begin{tabular}{|l|}
\hline Reference \\
\hline (Roos \& Victor, 1999) \\
\hline (Schrage, 2000) \\
\hline (Burg \& Roos, 2003) \\
\hline (Roos et al., 2004) \\
\hline Beech et al. (2004) \\
\hline Jacobs and Statler (2005) \\
\hline Buergi, Jacobs, and Roos (2005) \\
\hline Jacobs and Heracleous (2006) \\
\hline Jacobs and Statler (2006) \\
\hline Holliday, Statler, and Flanders (2007) \\
\hline Statler and Oliver (2008). \\
\hline Statler, Jacobs, and Roos (2008) \\
\hline
\end{tabular}

Table 1. The use of serious play in organizational contexts (Borrowed from Statler et al., 2011).

Serious play use is more prominent in strategy development rather in other organizational contexts due to the constant need for a better strategy for businesses to flourish in the constantly changing business environment (Roos \& Victor, 1999; Roos, Victor, \& Statler, 2004).

Regardless of the benefits that serious play could bring to the process of bridging theory and practice together, it still is a tool that satisfies more of strategy than any other organizational context, including the paradoxes of business.

Another aspect of practice that is often overlooked is Zen Buddhism Practice. It is a concept that can be a suitable candidate to help in the process of navigating paradox. Zen practice main connotation is an acceptance of anxiety, ambiguity, senseless and irrationality of things and positively carry on with the daily life matters while simultaneously watering and fostering anxiety, ambiguity, irrationality and many other dimensions through Koans all to the purpose, that is in most cases, reaching enlightenment (Kato, 2005). As Koans are the fuel to Zen practice, they also are the passing marks through gates for measuring mastery levels, to reach higher insights into not only the Zen philosophy and ultimately enlightenment, and understanding in other aspects of life (Didriksen, 2018; Purser, 2013; Suprun, Yanova, \& Nosov, 2013). The positioning of Koans in between apparent contradictions to push oneself beyond the known limits and beyond the known rationality is but a manifestation of selfless, goalless and often aimless pursuits, that in turn, ignite creativity, hone behaviour, encourage and encompass perspectives that before not recognized or not been proven to be of use for current issues (Kato, 2005; Low \& Purser, 2012; Pirsig, 1998; Purser, 2013; Suprun et al., 2013), while simultaneously provoke ambiguity, unclarity, meaninglessness and uncertainty that lead to frustration and doubt (Loori, 2006). The practice of Koans is of contradicting and of paradoxical nature (Didriksen, 2018; Loori, 2006; Suprun et al., 2013; Suzuki, 1988). Therefore, the practice of Koans deconstructs the limits of the current thinking perspectives and deals with problem in hands (Didriksen, 2018).

At a certain peak of mastery, enlightenment happens (Kato, 2005), practitioners break off limits and become awakened, that is translated as a state of mind in which the awakened and the enlightened understand that they achieved such a level by not seeking any particular goal or dream (Suprun et al., 2013)..

The concept of Zen practice is to train awareness with the help of Koans that in turn determine achievements and act as a meritocracy nexus between master and practitioner (Didriksen, 2018; Masuda \& O'Donohue, 2017), moreover, Koans can be considered tools that seek a simple and right answer for illogical and often times irrational practical questions that would contribute in stretching the boundaries of known limits and seek an answer out of the ordinary that satisfies both the polarities of a given issue that are also often oxymoronic, contradictory and 
paradoxical in nature. An example of such a Koan is the graduating practitioner that seeks final confirmation before leaving a monastery, the practitioner seeks the master and asks permission. The master replies with a gift that is a burning coal. Since the student can neither leave without accepting the gift nor refusing it. the practitioner after sometime decided to thank the master for the gift but decided to not take it (Didriksen, 2018) thus the practitioner broke the limits from having to deal with two options to choosing to extend the both into a third one while satisfying the both.

Koan practice offers insights into methods of combining theory with practice that has been practiced for a long time, Zen as a theory and its tools for practice are examples to follow when attempting to navigate paradox and set it in the hearts of business organizations. The question stays asked, considering the above insights from Zen, what would be the business Koans -or what I would call paradox pitch- that would push the leaders thinking to go beyond the existing limitations? Considering that navigating paradox can only be achieved by making the paradox tensions that are applied irrelevant, which can only be achieved by reaching to different level of thinking than the one we have achieved.

\section{Practice aspects of paradox}

Paradox has been the subject of interest of many authors who attempted finding ways, methods and approaches to navigate it and to make it exploitable in many fields including business, amongst these authors are Barry Johnson's Polarity Map identifying and managing unsolvable problems (Johnson, 1992) and Charles Handy, 1995 who depicted the story in a form of a sigmoid curve in which one, by applying its concept on given paradoxical issue, can subjectively interpret events, recognise patterns and apply solutions to given enigmas of a paradox based on the cycle of already known sequences such as life itself and life cycle of organizations (Handy, 1995). The above-mentioned authors have done a little bit more than just theoretical frameworks, where Johnson went a step further and actually digitized his polarity map model to be used in conjunction with the paradox theory available. Paradox prominence is apparent in every field (Guilmot \& Ehnert, 2015; Handy, 1995; Lewis, 2000; Smith \& Lewis, 2011; Smith \& Tushman, 2005). The way it is perceived differs from one individual to another; from the vast array of literature about paradox, we are ought to distinguish 3 different yet prominent definitions for paradox that are necessary to keep in mind when I delve deeper into the practical mode of paradox. According to J.L. Mackie 1973, paradox is a set of logically sane irregularities with a false conclusion. To Rescher 2001, Paradox is a dissonance in which each statements seems true; To Sainsbury 2009, paradox is a set of acceptable statements in which an unacceptable conclusion is derived (Mechiche, 2019). From these definitions, it is apparent that paradox is perceived differently amongst individuals and resolutions to these paradoxes amongst scholars and enthusiasts of paradox often time fall within the following approaches

- $\quad$ Finding flaws in the paradox's logic and/or reasoning

- Studying the etymology of the words in the premises of a paradox and finding flaws in the argumentation

- Neutrality when faced with paradox

- $\quad$ Nullifying the tensions of a paradox by using adversatives or adversative paradoxes

- Introduction of philosophical/theological solutions

- Observation and comparability to an existing model, framework, tradition, or approach

The above approaches cover a variety of paradoxes and some of these approaches are covered by the managerial stances in relation to Poole and Van de Ven's four options. Taking in consideration that Poole and Van de Ven's definition of paradox is rounded to the poles of contradictions manifesting in practice, and the stance of accepting paradox for what it is and pursuing the extent of its tensions (Poole \& van de Ven, 1989), is expected to yield novel responses that might at times satisfy at some extent the polarities of the undertaken paradox. However, the down side of literature on paradox is that it somehow has always taken refuge in leveraging insights from theory and ancient wisdoms, while it stayed silent concerning its practical aspects (Schad, Lewis, Raisch, \& Smith, 2016).

Therefore, for leaders to begin to engage the process of navigating paradox, it is crucially first and foremost to classify the paradoxes they are faced with. Not every paradox is what it seems, and not quite correct that theoretical approaches can help. Thus, considering the firm's dimensions and current state, the leader needs to screen and classify the paradox in hand before engaging in any attempts to navigate any of its tensions. This classification will help greatly in taking a step back and promote proper methodology while preventing leadership from giving in to the heat of the moment. The classification is as follows.

i. Paradoxes that appear when pursuing a goal: Such paradoxes appear during the journey to achieve a certain goal, idea, purpose or a concept of such, therefore, recognizing their existence and moving on is in line with Poole and Van de Ven's concept and more narrowly, refers to the plethora of paradoxes that are prominent when the requirements of certain business needs are met and the execution phase commences, for instance the paradoxes that arise in project management (Linetsky, 2008; Samset \& Volden, 2016). 
ii. Stimulating paradoxes: These paradoxes stimulate and challenge reason without or little physical applications due to the long chain of dependencies in which they are related to, such as the paradox of organizations outlined by Charles Handy, 1995, the paradox per se concerns knowing how to run organizations ,that includes all sorts of scenarios of having an organization small and/or big, centralized and decentralized, and the expectation of autonomy and team play (Handy, 1995). And the EPR paradox that was formulated as an experiment intended to demonstrate an inherent paradox in the early formulations of quantum theory studied by Margaret Cuonzo, where she concluded that “... discovering paradox, ironically, leads to advances in our knowledge"(Cuonzo, 2014. p-209)

iii. Paradoxes that are meant to be avoided and/or completely replaced: such paradoxes act as fuzzy mirrors to the real polarities that require attention. The daily issues that arise within organizations that by nature, are entirely or partially dependent on some aspect, department or business goal, or dependent on the organization as a whole, hence, the paradoxes such as the stupidity paradox in its different levels in an organization introduced by Alvesson and Spicer, 2016, and the paradox of productivity that was introduced by C. Handy, 1995. Examples are many and most prominent is the paradox of competition and cooperation that tends to rise in red and bloody oceans. This paradox already has a solution where both the tensions of the paradox are irrelevant, and become a choice and cease to be a necessity to navigate, and this solution is offered by Blue Ocean concept where the market belongs to the one who gets there first.

iv. Paradoxes that are known and might and/or might not be resolved (controversial paradoxes): such paradoxes are paradoxes where a solution is often times not required, nonetheless, their strong prominence persists and manifests in many aspects and in different dimensions such as the work paradox, productivity paradox and paradox of time (Bassi \& Fave, 2012; Brynjolfsson \& Hitt, 1998; Handy, 1995; Polák, 2017).

Classifying paradoxes as attempted above helps in clarifying some of the ambiguity, uncertainty and chaos that surround them. Once the class of a paradox in hand is known as to be such, the quest for navigating it is narrowed to the polarities of the paradox per se, that is, by definition of practice, a part of the process of materializing a given theoretical knowledge by means of achieving measurable results of any kind (Bourdieu, 1990; Howard, 2012b; Nicolini et al., 2003; Schatzki et al., 2001). Leaders are ought to gain insights into paradox nature, in other words, she can distinguish a paradox when encounters one, also, able to screen the paradox and classify it using the framework I introduced above. Thus, leader would roughly know what is it that she must navigate and be capable of filtering the paradoxes encountered while having a clear picture of the future actions to be taken.

Further on, it is indeed troublesome the quest for practice aspects of paradox due to the theory of practice shorthandedness towards paradox in business. Nonetheless, as to Lewin's belief, it is not enough to only to explain things; it is also necessary to get involved with them as well as involving others in the process of understanding and in changing them (Coghlan \& Brannick, 2003). For this matter, choosing to get involved with paradox entails that one would require a mental practice or in conformity to the stream of this paper an intellectual practice which by definition is that the process needs to involve a certain level of mental and intellectual activities that are directly related to practicing paradox considering the scarcity of literature in this domain.

Brain plasticity as a research field gives a scientific hope for intellectual practice thanks to many pioneers in the field and amongst them Dr. Kolb who confirmed that there is doubt that even thoughts can alter the brain (Kolb, 1995); therefore, the intellectual practice referred to consists of the proper exercise of one's intellectual aptitudes (Floyd, 2010), which in turn, ignites series of changes on different levels in the brain that is called plasticity (Kolb \& Gibb, 2014), to finally prepare it for the task in hand, in other words, bear and navigate the paradoxical tensions in hand once willingly chosen to.

Practice aspects of paradox are simultaneously latent and salient. On one hand, literature supports that paradox is the way to novelty, on the other hand, it is hard to find literature that pinpoints the tasks and activities to follow to practice navigating paradox. Prominent authors such as Barry Johnson 1992, Fletcher 1997 and Handy 1995, Bob De Wit 2018 have set intellectual frameworks for managing the paradox tensions that arise.

\section{The means and the ends}

Paradox is paradox, if one calls it or undertakes it wrong, he opposes its reality and if he does not, he ignores its fact in the age of the need to standardize, conform and conclude. Reaching beyond existing limitations to seek novel solutions means navigating a way through the ambiguity, complexity and the chaos paradoxical tensions impose (Handy, 1995; Quinn, 1991; Sainsbury, 1995; Sorensen, 2003). Therefore, the need to determine the how of the process of navigating paradox and assigning it to practical approach, steps and/or guidelines is vital. Brain plasticity dictates that a change in behaviour towards doing a certain task ignites the plasticity abilities of the brain to adjust to the chosen behaviour (Costandi, 2016; Doidge, 2008; Kolb, Teskey, \& Gibb, 2010; Kolb \& Whishaw, 1998; Lövdén, Wenger, Mårtensson, Lindenberger, \& Bäckman, 2013; Marzouk, 2017; Rivera, Carlson, \& David Zelazo, 2017). Thus, an intellectual practice is a key to both changing a behaviour and to igniting plasticity. 
To initiate a behaviour change journey to navigate paradox, some prerequisite tasks need to be performed and some basic skills need to learnt, the following are some steps if used in conjunction with the classification of paradox proposed earlier in this paper, could help leaders greatly in starting their journey to successfully reach a level of understanding where the paradox tensions become irrelevant and where novelty, creativity and limitless thinking take over.

- Paradoxical cognition: is the ability to recognize paradoxical tensions. It is necessary to practice and develop this stream because when contemplating on business issues the need to exercise a thinking process that supports the idea that issues tend to have more than one side, but also, are presented in series of polarities. This skill needs to be nurtured to the level of instinctively cognize polarities even in the easiest of problems.

- Paradoxical observation: Being able to observe and see patterns in the way paradox tensions present themselves and/or are presented could be a very important intellectual practice that will result in skills that will contribute in stretching the four classifications of paradox that I have introduced in this paper. (Mechiche, 2019).

These prerequisites to intellectual practice ultimately complement a learning model is necessary is because of remember, recognize patterns, and learn from mistakes. The purpose of the learning model is to identify steps in details on how to engage and learn from the journey to navigate paradox. It sets the steps in a way that overlap one another, in a sense that encourages intellectual practice as well as experimentation. Nonetheless, to be able to achieve results using this cycle, an environment in which the harsh repercussions of reality do not affect the self-development and the will to navigate paradox is of utmost importance.

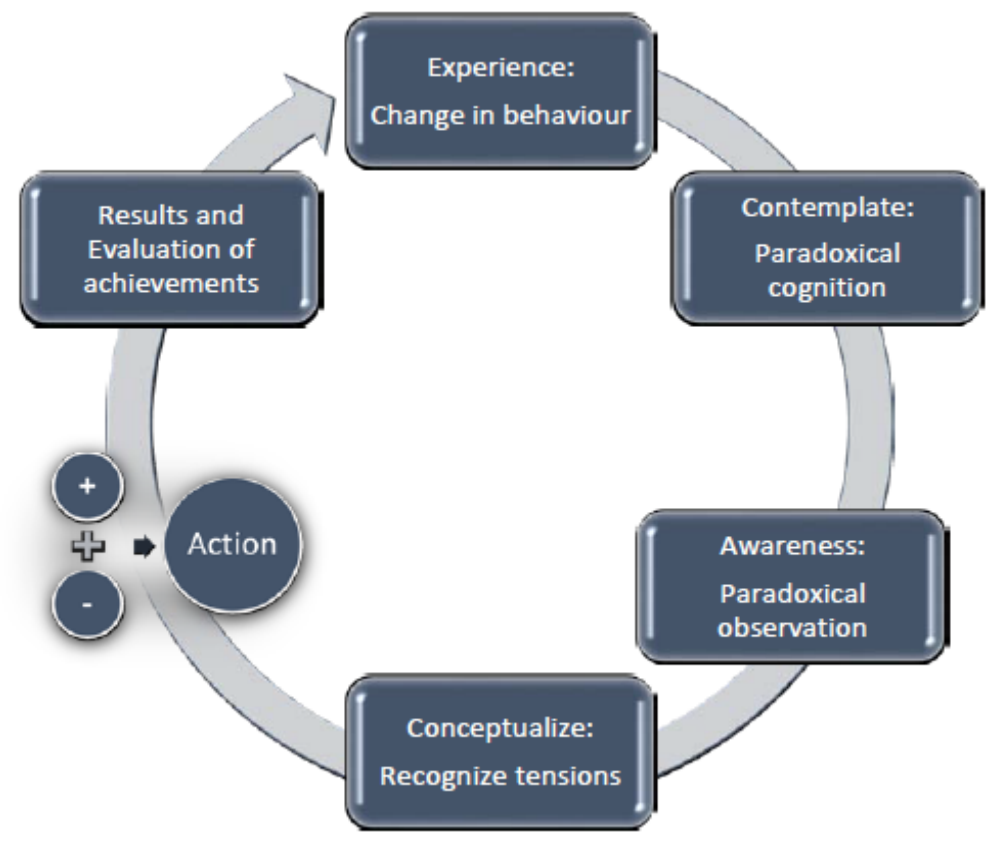

Figure 1. Learning model to navigate paradox in business

To further deepen the understanding on how navigating paradox in the future would be shaped, I would introduce "Paradox pitch". Paradox pitch apart from Zen Koans are a conceptual framework of action-orienting process. In other words, having a Paradox pitch in hand would mean that the real paradoxical tensions have been identified and the next step is to formulate it in a way that would stimulate the formulation of an answer that satisfies two simultaneously divergent goals, tensions and/or in part or in whole would satisfy the paradox either in short or long term or even push the thinking to a whole different level where none of the former is irrelevant.

Koans according to literature open gates to enlightenment (Didriksen, 2018; Kato, 2005; Low and Purser, 2012; Purser, 2013; Suprun et al., 2013). To pick on this principle and using comparability of the concept with the business domain, I believe that by suggesting Paradox Pitch that is formulated as an abstract tele-psychological question/puzzle with a goal of seeking answers that satisfy two divergent goals simultaneously would open gates to mastery. Mastery according to Quinn is "... a capacity to continuously hold, test and experiment with opposing conceptualizations of reality" (Quinn, 1988, p. 12). Therefore, based on these insights, it is fair to conclude that the more an individual is exposed to such pitches, the more adequate one's brain becomes to host the newly engaged tasks, experiments and/or practice. Therefore, with respect to brain plasticity conclusions, the more time one spends in trying to navigate paradox, the better one gets at navigating it. 


\section{Conclusion}

Despite the fact that the yield of knowledge from literature available on paradox is much less when the search digresses from paradox theory to paradox practice in the purpose of getting better it in any manner, i.e. accepting it, flirting with it, and managing it.

The paradox pendulum seems to be swinging around some generally accepted theoretical concepts that revolve around a countable number such as, Juxtaposing, parallel processing, trade off, mapping and some others.

This paper was dedicated to the exploration of possible practice approach to paradox in the real world, and streams of practice that could lead to a successful implementation of paradox in business organizations. The paper takes insights from research on brain plasticity and in behaviour on the brain's ability to restructure itself in order to allow a newly adopted behaviour to thrive (Doidge, 2008; Kolb \& Gibb, 2014; Kolb \& Whishaw, 1998; Lövdén et al., 2013), research on paradox theory and research on Zen psychology and philosophy in the quest of implementing a similar approach as Koans in translating the business paradox an organization is facing. In this regard, I have introduced paradox pitch that does a similar function by comparability to concept of Zen koans.

Paradox pitch is an approach to express both tensions of a paradox in such a way that promotes irrationality and attempts to promote thinking that is simply different. It will involve a juxtaposition of two or more divergent goals, polarities, dilemmas etc. ... in a form of text or a question to be asked to oneself and/or to an organization's personnel.

Along the process, this paper sheds light on some existing streams of practice, research on logic of practice and on some classification of paradox that in theory, should help a firm's diagnosing process to reaching the real paradoxical tensions that are exerted on the business.

The literature explored revealed that there is a lack in research on the practice aspects of paradox, it also points out the need of such stream to be explored deeper and to be taken seriously regardless of the nature of paradox. Because insights from brain plasticity give hope that no matter how difficult a task can be, the more an individual practices it, the better s/he gets better at it. Thus, individuals are already equipped with what is necessary to understand paradox. Paradox pitch offers a way on how to approach paradox tensions and what is left is the willingness to adopt such stream and responsibility that one should take when engaging polarities.

\section{Final Thoughts}

Navigating paradox does not only entail a solution to the problems that we face every day, also it changes the nature of the problems that we had, have and/or having yet involves us in a thinking that is apart from the one we are used to. It takes us to a level where experience/reason and theory/practice coopete to deliver answers that converge the divergent goals of a paradoxical tension along the way, we notice a change in our behaviour, a new sharp and honed culture in organizations and a whole new set of problems that we did not even know they existed arise as we exploit more and more of paradox powers. In this regard, we would only know that we are navigating paradox when the initial paradoxical tensions we were faced with become completely irrelevant. This means that our understanding has broken off to a different understanding, thanks to the tensions of the polarities, and the issues we thought were intense at the time, completely fade away to leave room for a whole new set of problems and solutions. Hence, it is a very crucial performance indicator and success factor that any leader should take under very serious consideration, because if not, the polarity per se becomes the limitation that will make the leader dwell, where it acts as blinkers and prevents our thinking from breaking free, and rejects any other understanding that is apart from that we know. For this matter, I believe that paradox, any paradox for that matter, is a paradox of its own and we owe it to ourselves to seek navigating it by all means necessary including adapting our behaviour to adjust to its tensions. By doing so, the rest falls in place and the process to demystify its powers begins

\section{References}

Alvesson, M., \& Spicer, A. (2016). The Stupidity Paradox: The Power and Pitfalls of Functional Stupidity at Work. Profile Books.

Bassi, M., \& Fave, A. D. (2012). Optimal Experience Among Teachers: New Insights Into the Work Paradox. The Journal of Psychology, 146(5), 533-557. https://doi.org/10.1080/00223980.2012.656156

Beech, N., Burns, H., de Caestecker, L., MacIntosh, R., \& MacLean, D. (2004). Paradox as invitation to act in problematic change situations. Human Relations, 57(10), 1313-1332. https://doi.org/10.1177/0018726704048357

Bourdieu, P. (1990). The Logic of Practice. Stanford University Press.

Brulhart, F., Grimand, A., Krohmer, C., Oiry, E., \& Ragaigne, A. (2018, February). Management des paradoxes: Compétences, performances et outils de gestion. Revue Française de Gestion; Paris, 44(270), 65-69.

Brynjolfsson, E., \& Hitt, L. M. (1998). Beyond the productivity paradox. Communications of the ACM, 41(8), 4955. https://doi.org/10.1145/280324.280332

Clegg, S. R., Vieira de Cunha, J., \& Cunha, M. P. e. (2002). Management paradoxes: A relational view. Human Relations; Thousand Oaks, 55(5), 483-503. 
Coghlan, D., \& Brannick, T. (2003). Kurt Lewin: The "Practical Theorist" for the 21 st Century. Irish Journal of Management, 24(2), 31-37.

Costandi, M. (2016). Neuroplasticity. MIT Press.

Cuonzo, M. (2014). Paradox. MIT Press.

Czakon, W., Fernandez, A.-S., \& Minà, A. (2013). Editorial - From paradox to practice: The rise of coopetition strategies. International Journal of Business Environment. (world). Retrieved from http://www.inderscienceonline.com/doi/abs/10.1504/IJBE.2014.058040

Didriksen, L. S. (2018). A Paradox of Koan Study and Why Psychology Should Take Note. Human Arenas, 1(4), 396-408. https://doi.org/10.1007/s42087-018-0036-4

Doidge, N. (2008). The Brain That Changes Itself: Stories of Personal Triumph from the Frontiers of Brain Science. Penguin UK.

Fletcher, J., \& Olwyler, K. (1997). Paradoxical Thinking: How to Profit from Your Contradictions. BerrettKoehler Publishers.

Floyd, S. (2010). Education as Soulcraft: Exemplary Intellectual Practice and the Cardinal Virtues. Studies in Christian Ethics, 23(3), 249-266. https://doi.org/10.1177/0953946810368022

Guilmot, N., \& Ehnert, I. (2015). 27 years of research on organizational paradox and coping strategies: A review. 24.

Handy, C. B. (1995). The Age of Paradox. Harvard Business Press.

Hart, W. D. (2006). [Review of Review of A Brief History of the Paradox, by R. Sorensen]. Mind, 115(458), 488491. JSTOR. Retrieved from JSTOR.

Howard, R. W. (2012a). Longitudinal Effects of Different Types of Practice on the Development of Chess Expertise. Applied Cognitive Psychology, 26(3), 359-369. https://doi.org/10.1002/acp.1834

Howard, R. W. (2012b). Longitudinal Effects of Different Types of Practice on the Development of Chess Expertise. Applied Cognitive Psychology, 26(3), 359-369. https://doi.org/10.1002/acp.1834

Johnson, B. (1992). Polarity Management: Identifying and Managing Unsolvable Problems. Human Resource Development.

Kato, H. (2005). Zen and psychology. Japanese Psychological Research, 47(2), $125-136$. https://doi.org/10.1111/j.1468-5884.2005.00280.x

Kolb, B. (1995). Brain Plasticity and Behavior. Psychology Press.

Kolb, B., \& Gibb, R. (2014). Searching for the principles of brain plasticity and behavior. Cortex, 58, 251-260. https://doi.org/10.1016/j.cortex.2013.11.012

Kolb, B., Teskey, G. C., \& Gibb, R. (2010). Factors Influencing Cerebral Plasticity in the Normal and Injured Brain. Frontiers in Human Neuroscience, 4. https://doi.org/10.3389/fnhum.2010.00204

Kolb, B., \& Whishaw, I. Q. (1998). Brain plasticity and behavior. Annual Review of Psychology, 49(1), 43.

Kouzes, J. M., \& Posner, B. Z. (1995). The leadership challenge: How to keep getting extraordinary things done in organizations. Jossey-Bass.

Lewis, M. W. (2000). Exploring Paradox: Toward a More Comprehensive Guide. Academy of Management Review, 25(4), 760-776. https://doi.org/10.5465/AMR.2000.3707712

Linetsky, B. L. (2008). The Project Management Paradox: Achieving More by Doing Less. Ivey Business Journal (Online); London, 72(2), N A.

Loizos Heracleous, C. J. (2005). The Serious Business of Play. MIT Sloan Management Review; Cambridge, 47(1), $19-20$.

Loori, J. D. (2006). Sitting with Koans: Essential Writings on Zen Koan Introspection. Simon and Schuster.

Lövdén, M., Wenger, E., Mårtensson, J., Lindenberger, U., \& Bäckman, L. (2013). Structural brain plasticity in adult learning and development. Neuroscience \& Biobehavioral Reviews, 37(9, Part B), 2296-2310. https://doi.org/10.1016/j.neubiorev.2013.02.014

Low, A., \& Purser, R. (2012). Zen and the creative management of dilemmas. Journal of Management, Spirituality \& Religion, 9(4), 335-355. https://doi.org/10.1080/14766086.2012.744543

Marzouk, S. (2017). S182 Introduction to neuroplasticity and its application in neurorehabilitation. Clinical Neurophysiology, 128(9), e237. https://doi.org/10.1016/j.clinph.2017.07.192

Masuda, A., \& O’Donohue, W. T. (2017). Handbook of Zen, Mindfulness, and Behavioral Health. Springer.

Mechiche. (2019). Mourad Mechiche-PARADOX IN BUSINESS Towards a practical utility for paradox in business organizations-E-Theses_-The Tritonia Academic Library, Vaasa. Retrieved April 2, 2019, from https://www.tritonia.fi/en/etheses/abstract/8606/PARADOX+IN+BUSINESS++Towards+a+practical+utility+for+paradox+in+busines $\mathrm{s}+$ organizations

Neuwirth, R. J. (2018). Law in the Time of Oxymora: A Synaesthesia of Language, Logic and Law. Routledge. https://doi.org/10.4324/9781351170208

Nicolini, D., Gherardi, S., \& Yanow, D. (2003). Knowing in Organizations: A Practice-based Approach. London, 
England: M.E. Sharpe.

Pirsig, R. (1998). Basis of Zen practice. BMJ : British Medical Journal, 317(7170), 1442.

Polák, P. (2017). The productivity paradox: A meta-analysis. Information Economics and Policy, 38, 38-54. https://doi.org/10.1016/j.infoecopol.2016.11.003

Poole, M. S., \& van de Ven, A. H. (1989). Using Paradox to Build Management and Organization Theories. Academy of Management Review, 14(4), 562-578. https://doi.org/10.5465/AMR.1989.4308389

Purser, R. E. (2013). Zen and the Art of Organizational Maintenance. 2(1), 40.

Quinn, R. E. (1988). Beyond rational management: Mastering the paradoxes and competing demands of high performance. Jossey-Bass.

Quinn, R. E. (1991). Beyond Rational Management P: Mastering the Paradoxes and Competing Demands of High Performance (New Ed edition). San Francisco: John Wiley \& Sons.

Rivera, S. M., Carlson, S. M., \& David Zelazo, P. (2017). Introduction to Special Issue: "Current Perspectives on Neuroplasticity." Cognitive Development, 42, 1-3. https://doi.org/10.1016/j.cogdev.2017.05.003

Roos, J., \& Victor, B. (1999). Towards a new model of strategy-making as serious play. European Management Journal, 17(4), 348-355. https://doi.org/10.1016/S0263-2373(99)00015-8

Roos, J., Victor, B., \& Statler, M. (2004). Playing seriously with strategy. Long Range Planning, 37(6), 549-568. https://doi.org/10.1016/j.lrp.2004.09.005

Sainsbury, R. M. (1995). Paradoxes. Cambridge; New York: Cambridge University Press.

Samset, K., \& Volden, G. H. (2016). Front-end definition of projects: Ten paradoxes and some reflections regarding project management and project governance. International Journal of Project Management, 34(2), 297-313. https://doi.org/10.1016/j.ijproman.2015.01.014

Schad, J., Lewis, M. W., Raisch, S., \& Smith, W. K. (2016). Paradox Research in Management Science: Looking Back to Move Forward. Academy of Management Annals, 10, 5-64. https://doi.org/10.1080/19416520.2016.1162422

Schatzki, T. R. (2012). A Primer on Practices. In J. Higgs, R. Barnett, S. Billett, M. Hutchings, \& F. Trede (Eds.), Practice-Based Education: Perspectives and Strategies (pp. 13-26). Rotterdam: SensePublishers. https://doi.org/10.1007/978-94-6209-128-3_2

Schatzki, T. R., Knorr-Cetina, K., \& Savigny, E. von. (2001). The Practice Turn in Contemporary Theory. Psychology Press.

Smith, W. K., \& Lewis, M. W. (2011). Toward a Theory of Paradox: A Dynamic Equilibrium Model of Organizing Academy of Management Review, 36(2), 381-403. https://doi.org/10.5465/AMR.2011.59330958

Smith, W. K., \& Tushman, M. L. (2005). Managing Strategic Contradictions: A Top Management Model for Managing Innovation Streams. Organization Science, $16(5), \quad 522-536$. https://doi.org/10.1287/orsc.1050.0134

Sorensen, R. (2003). A Brief History of the Paradox: Philosophy and the Labyrinths of the Mind. Oxford University Press.

Sundaramurthy, C., \& Lewis, M. (2003). Control and collaboration: Paradoxes of governance. Academy of Management. The Academy of Management Review, 28(3), 397-415.

Suprun, A. p., Yanova, N. g., \& Nosov, K. a. (2013). Zen Psychology: Koans. Journal of Russian \& East European Psychology, 51(5/6), 49-135. https://doi.org/10.1080/10610405.2013.1054238

Suzuki, D. T. (1988). An introduction to Zen Buddhism (Repr). Rider.

Trottier, K., Polivy, J., \& Herman, C. P. (2009). Effects of Resolving to Change One's Own Behavior: Expectations vs. Experience. Behavior Therapy, 40(2), 164-170. https://doi.org/10.1016/j.beth.2008.05.004 